\title{
Enteroparasitism in Hard-to-Reach Community Dwellers: A Cross-Sectional Study in Ga West Municipality in Ghana
}

\author{
Enoch Aninagyei $\mathbb{D}^{1},{ }^{1}$ Ruby Yirenkyi, ${ }^{2}$ Tanko Rufai, ${ }^{3,4}$ and Margaretta Gloria Chandi ${ }^{5}$ \\ ${ }^{1}$ Department of Biomedical Sciences, School of Basic and Biomedical Sciences, University of Health and Allied Sciences, Ho, \\ Volta Region, Ghana \\ ${ }^{2}$ Department of Molecular Biology and Biotechnology, University of Cape Coast, Cape Coast, Ghana \\ ${ }^{3}$ Ghana Health Service, Accra, Ghana \\ ${ }^{4}$ New Juabeng Municipal Health Directorate, Koforidua, Ghana \\ ${ }^{5}$ Ga North Municipal Health Directorate, Ofankor-Accra, Greater Accra Region, Ghana
}

Correspondence should be addressed to Enoch Aninagyei; eaninagyei@uhas.edu.gh

Received 15 June 2020; Revised 20 August 2020; Accepted 21 August 2020; Published 24 September 2020

Academic Editor: Bernard Marchand

Copyright (c) 2020 Enoch Aninagyei et al. This is an open access article distributed under the Creative Commons Attribution License, which permits unrestricted use, distribution, and reproduction in any medium, provided the original work is properly cited.

Ga West Municipality in Ghana is predominantly rural with about forty-eight hard-to-reach communities. Several infectious diseases such as Buruli ulcer, tuberculosis, yaws, schistosomiasis, and malaria are prevalent in the municipality. However, the prevalence and characteristics of enteroparasites in the municipality are unknown. Therefore, this cross-sectional study determined the prevalence of enteroparasites in these hard-to-reach communities. Samples were collected from five communities, namely, Opah, Otuaplem, Dedeman, Onyansana, and Manchie. A total of 538 stool samples were collected from the community dwellers. Each sample was examined with eosin-saline wet preparation and formol-ether concentration technique. Body mass index, haemoglobin, and albumin concentrations were used to assess nutritional status. Seven different parasite species were identified in 178 community dwellers (33.1\% prevalence (95\% CI: $0.29-0.37)$ ). The individual prevalence of the identified parasites was Schistosoma mansoni (13.4\%), Entamoeba histolytica (7.2\%), Ascaris lumbricoides (6.9\%), Giardia lamblia (5.0\%), hookworm (4.8\%), Strongyloides stercoralis (4.8\%), and Balantidium coli (1.6\%). Among the 178 parasitized individuals, $68.0 \%$ were singly infected while $31.5 \%$ had dual parasitism. Significantly higher infections were associated with Onyansana dwellers $(p=0.019)$, participants aged $16-20$ years $(p=0.006)$, unmarried participants $(p<0.001)$, those without formal education $(p=0.044)$, and crop farmers $(p=0.044)$. However, among the Akan tribe $(p=0.015)$, Christians $(p=0.03)$, and participants with higher incomes $(p=0.012)$, infections were found to be lower. Compared to monoparasitism, dual parasitism was significantly associated with underweight (17.8 vs. $\left.20.3 \mathrm{~kg} / \mathrm{m}^{2}\right)$, anaemia $(7.7 \mathrm{vs.} 9.8 \mathrm{~g} / \mathrm{dL})$, and malnutrition (27.6 vs. $31.9 \mathrm{~g} / \mathrm{L}$ of albumin concentration). These findings underscore the fact that the Ga West Municipality is heavily burdened with different species of enteroparasites. Therefore, education on personal hygiene to reduce parasitic infections must be intensified while implementing regular mass deworming exercise in the municipality.

\section{Introduction}

Ga West Municipality is one of the sixteen districts in the Greater Accra Region of Ghana. The municipality is $60 \%$ rural, $25 \%$ periurban, and $15 \%$ urban. It is made up of about 150 communities with Amasaman as its municipal capital [1]. It occupies a total land surface area of about 300 square kilometers with an estimated population of 262,742 as of
2015 [2]. Of the 150 communities in the municipality, about 48 communities (32\%) are hard-to-reach. These hard-toreach communities have been cut off from other communities by poor road infrastructure and defective bridges. In rainy seasons (mid-May to July), these roads are not motorable. These communities lack good health facilities with educational facilities only at the basic school level. Also, some basic social amenities are lacking. Potable water is lacking in 
almost all of these hard-to-reach communities except water from hand-operated wells and dug-outs in some "fortunate" communities. Residents rely mostly on rivers and streams for survival [3].

Some infectious diseases are very prevalent in the municipality, and residents in these hard-to-reach communities are mostly affected. Buruli ulcer, a disease caused by Mycobacterium ulcerans, is highly prevalent in these communities $[1,4]$ as well as yaws, a tropical disease caused by Treponema pertenue [5]. In these communities, tuberculosis, caused by Mycobacterium tuberculosis [6, 7], has also been found to be prevalent. Parasitic diseases such as malaria [8] and schistosomiasis $[8,9]$ are very common in the municipality, particularly in these poor communities.

Despite high prevalence of these infectious diseases in these communities, the burden of enteroparasites is unknown, hence scarcity of data in this regard. Therefore, this study was designed to determine the prevalence of enteroparasites in residents of these hard-to-reach communities in the Ga West Municipality of the Greater Accra Region of Ghana and also to determine some factors and clinical effects that are associated with enteroparasitism in parasitized individuals.

\section{Methods}

2.1. Study Design and Study Plan. This observational study, conducted between September 2019 and March 2020, was carried out to determine the prevalence of enteroparasites in selected communities in Ghana. Demographic indicators associated with parasitism were explored. Also, the effects of enteroparasitism on parasitized individuals were described. A list of hard-to-reach communities was obtained from the Ga West Municipal Health Administration.

2.2. Description of Study Areas. This study was done in hardto-reach communities in the Ga West Municipality in the Greater Accra Region of Ghana. The communities were Opah, Otuaplem, Dedeman, Onyansana, and Manchie (Figure 1). These five communities were blindly selected from a list of about 48 communities in a simple random manner. From the municipal capital, Amasaman, where the municipal hospital was located, Opah, Manchie, Onyansana, Dedeman, and Otuaplem are about $16 \mathrm{~km}, 19 \mathrm{~km}, 20 \mathrm{~km}$, $26 \mathrm{~km}$, and $28 \mathrm{~km}$ away, respectively. These communities are connected to the municipal capital by poor road networks. By road, it takes approximately 45 minutes to travel from Opah to Amasaman and about 2 hours to travel from the other four communities to Amasaman. These are predominantly farming communities with uncoordinated sand winning activities. None of these communities has either a hospital or a clinic. In Ghana, the basic health care facility is community-based health services (CHPS). These hard-toreach communities do not have a CHPS compound. Residents travel to nearby communities to assess community health services.

2.3. Selection of Households, Study Participants, and Stool Sample Collection. With the help of the community leaders, each household was numbered after which $10 \%$ of households were randomly selected to select participants from. Consent to include the household in the study was sought from the heads of the household. Consent to participate was also obtained from all participants and assent for participants under 18 years obtained from their guardians. After obtaining consent, the number of household occupants was noted and half of that number, to the nearest whole number, was sampled. A number of stool containers corresponding to half the number of household occupants were given to the heads of the household to be given, randomly, to the occupants for provision of about $4 \mathrm{~g}$ stool samples. The heads of the household were taken through proper stool sample collection protocols. Briefly, during defecation, the prelabelled stool container was opened, with the aid of the accompanying plastic disposable spoon; at least five spoonfuls were collected into the container. In the case of watery stool, containers were filled, using the disposable plastic funnel provided, to about one-third, without soiling the container. After sample collection, household heads ensured that the hands were properly washed and disinfected with a hand sanitizer containing 70\% alcohol. Stool samples were provided by participants early in the morning, placed in a prelabelled biohazard bag, and kept in a biohazard container. Samples were collected by $10 \mathrm{am}$ and sent to the laboratory.

2.3.1. Sample Size Determination. The minimum number of samples collected from the study sites was determined using the formula $n=z^{2} p(1-p) / d^{2}$, where $n$ is the sample size, $p$ $=$ prevalence of enteroparasitism in Ga West Municipality, $z$ $=$ confidence level at 95\% (standard value of 1.96), and $d=$ margin of error at 5\% (standard value of 0.05) [10]. Prevalence of enteroparasitism in Ga West is unknown, so prevalence was estimated at $50 \%$. The sample size was calculated to be 384 . To cater for missing and incomplete data, the sample size was increased by $10 \%$. Therefore, the minimum sample size was 423 .

2.3.2. Inclusion and Exclusion Criteria. Households included in this study were household with available heads to consent to the study. Also, participants included in the study were household occupants over five years old and those that have stayed in the community for at least a year. On the other hand, residents that have dewormed, using a Ministry of Health-approved dewormer, were excluded. Finally, household occupants that dissented participation and individuals that declined blood sample collection were also excluded.

2.4. Stool and Blood Sample Collection and Collection of Relevant Study Information. Early in the morning of sample provision, the research team was in the household to collect stool and blood samples and then administer a questionnaire to obtain some information from the study participant. Information obtained from the participants was age, gender, highest education, and occupation. Stool samples were divided into two equal parts; one part was fixed in $10 \%$ formol-saline solution and the other left unfixed. A sample pair was kept at ambient temperature prior to arrival in the Ga North Municipal laboratory. Whole blood was collected 


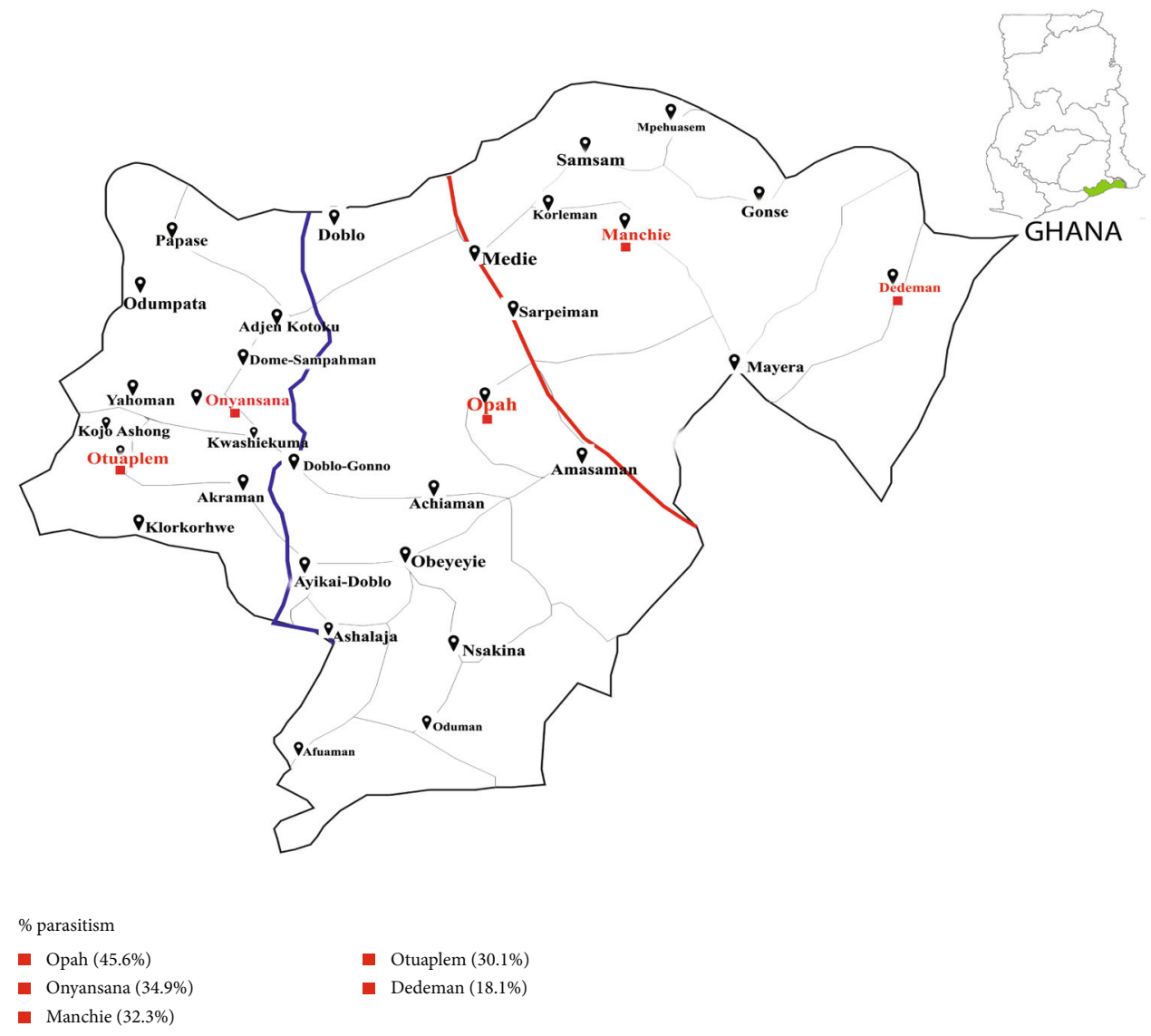

Figure 1: Map of Ga West Municipality, Ghana, showing study sites in red and prevalence of parasitism in study communities (the map is the authors' own production).

from a prominent vein at the antecubital fossa region of the forearm. Prior to blood collection, the selected area to perform venepuncture was disinfected with $70 \%$ alcohol and allowed to air dry before performing venepuncture. Five $\mathrm{mL}$ of whole blood was collected into the EDTA tube, mixed gently, and kept on ice till plasma was separated into another tube.

2.5. Nutritional Assessment. Body mass index (BMI), haemoglobin, and albumin concentrations were used to assess the nutritional status of the participants as previously used $[11,12]$.

2.5.1. Determination of Body Mass Indices. BMI was calculated by dividing the weight in kilograms $(\mathrm{kg})$ by the square of height in meters. Height was taken by a Seca 213 portable stadiometer (New Zealand), and body weight was taken by an Omron digital weighing scale (Omron, Kyoto, Japan). Height was taken barefooted, and weight was also taken in light cloths. Participants with BMI in $\mathrm{kg} / \mathrm{m}^{2}<$ $18.5,18.5-24.9,25.0-29.9$, and $>30.0$ were classified as underweight, normal, overweight, and obese, respectively, according to [13].

2.5.2. Determination of Haemoglobin Concentration. Haemoglobin concentration was determined by using a hand-held haemoglobinometer (URIT-12, Guangzhou, China). Prior to first use, the meter was calibrated using the accompanying calibration chip. The haemoglobin concentration was determined following the manufacturer's instruction. Briefly, a strip was inserted into the meter till the drop of blood sign appears on the screen; a drop of well-mixed anticoagulated blood was dropped on the sample receptacle portion of the strip. A result was obtained in about $5 \mathrm{sec}-$ onds. Haemoglobin levels $<8.0 \mathrm{~g} / \mathrm{dL}, 8.0-10.9 \mathrm{~g} / \mathrm{dL}, \quad 11.0-$ $11.9 \mathrm{~g} / \mathrm{dL}$, and $>12.0 \mathrm{~g} / \mathrm{dL}$ were classified as severe anaemia, moderate anaemia, mild anaemia, and nonanaemic, respectively, according to a World Health Organization publication on haemoglobin concentrations for the diagnosis of anaemia and assessment of severity [14].

2.5.3. Determination of Albumin Concentration. The albumin concentration was measured by a PKL-125 Italia fully automated chemistry analyser using an ELItech albumin endpoint reagent (France) based on the reaction: albumin + bromocresol green (BCG) $\rightarrow$ albumin-BCG complex.

The albumin-BCG complex absorbs maximally at $630 \mathrm{~nm}$. Albumin values below mean minus 1SD and above mean minus 2SD indicated malnourishment while values below mean minus $2 \mathrm{SD}$ indicated severe malnourishment. Classification was adopted from Omitola et al. [15]. 
TABLE 1: Association of prevalence of enteroparasitism with sociodemographic variables.

\begin{tabular}{|c|c|c|c|c|c|}
\hline \multirow{2}{*}{ Demographic characteristics } & \multirow{2}{*}{ Number of samples } & \multicolumn{2}{|l|}{ Prevalence of parasitism } & \multicolumn{2}{|l|}{ Chi-squared test } \\
\hline & & Number of infected individuals & $\%$ & Chi-squared value $\left(\chi^{2}\right)$ & $p$ value \\
\hline Resident community & & & & 21.9 & $<0.0001$ \\
\hline Opah & $149(27.7 \%)$ & 68 & 45.6 & & \\
\hline Otuaplem & $136(25.3 \%)$ & 41 & 30.1 & & \\
\hline Dedeman & $105(19.5 \%)$ & 19 & 18.1 & & \\
\hline Onyansana & $83(15.4 \%)$ & 29 & 34.9 & & \\
\hline Manchie & $65(12.1 \%)$ & 21 & 32.3 & & \\
\hline Gender & & & & 1.1 & 0.301 \\
\hline Males & $331(61.5 \%)$ & 115 & 55.5 & & \\
\hline Females & $207(38.5 \%)$ & 63 & 19.0 & & \\
\hline Age range (years) & & & & 89.9 & $<0.0001$ \\
\hline $6-10$ & $57(10.6 \%)$ & 30 & 52.6 & & \\
\hline $11-15$ & $118(21.9 \%)$ & 37 & 31.5 & & \\
\hline $16-20$ & $110(20.4 \%)$ & 69 & 62.7 & & \\
\hline $21-25$ & $79(14.7 \%)$ & 21 & 26.5 & & \\
\hline $26-30$ & $89(16.5 \%)$ & 9 & 10.1 & & \\
\hline $31-35$ & $41(7.6 \%)$ & 7 & 17.1 & & \\
\hline $36-40$ & $25(4.6 \%)$ & 2 & 8.0 & & \\
\hline$>40$ & $19(3.5 \%)$ & 3 & 15.8 & & \\
\hline Marital status & & & & 67.9 & $<0.0001$ \\
\hline Single & $188(34.9)$ & 105 & 55.9 & & \\
\hline Married & $294(54.6)$ & 63 & 21.4 & & \\
\hline Widowed & $18(3.3)$ & 3 & 16.7 & & \\
\hline Divorced & $38(7.1)$ & 7 & 18.4 & & \\
\hline Tribe & & & & 61.8 & $<0.0001$ \\
\hline Akan & $59(11.0)$ & 8 & 13.6 & & \\
\hline $\mathrm{Ga}$ & $87(16.2)$ & 32 & 36.8 & & \\
\hline Ewe & 279 (51.9) & 71 & 25.4 & & \\
\hline Dagomba & $33(6.1)$ & 17 & 51.5 & & \\
\hline Fulani & $71(13.2)$ & 48 & 67.6 & & \\
\hline Others $^{\mathrm{a}}$ & $9(1.7)$ & 2 & 22.2 & & \\
\hline Religion & & & & 91.1 & $<0.0001$ \\
\hline Christianity & $282(52.4)$ & 66 & 23.4 & & \\
\hline Islamic & $192(35.7)$ & 91 & 47.4 & & \\
\hline Traditional & $49(9.1)$ & 19 & 38.8 & & \\
\hline Others $^{\mathrm{b}}$ & $15(2.8)$ & 2 & 13.3 & & \\
\hline Average monthly income ${ }^{c}$ & & & & 38.4 & $<0.0001$ \\
\hline $0-500(0-90)$ & $120(28.9)$ & 56 & 46.7 & & \\
\hline $501-1000(91-181)$ & $82(19.8)$ & 33 & 40.2 & & \\
\hline $1001-1500(182-272)$ & $78(18.8)$ & 29 & 37.2 & & \\
\hline $1501-2000(273-363)$ & $59(14.2)$ & 13 & 22.0 & & \\
\hline$>2000(>364)$ & $76(18.3)$ & 9 & 11.8 & & \\
\hline Highest education & & & & 37.1 & $<0.0001$ \\
\hline None & $93(17.3 \%)$ & 53 & 56.9 & & \\
\hline Primary & $181(33.6 \%)$ & 61 & 33.7 & & \\
\hline Junior high & $153(28.4)$ & 33 & 21.6 & & \\
\hline Senior high & $89(16.5 \%)$ & 28 & 31.5 & & \\
\hline Postsenior high & $22(4.1 \%)$ & 3 & 13.6 & & \\
\hline
\end{tabular}


TABLE 1: Continued.

\begin{tabular}{|c|c|c|c|c|c|}
\hline \multirow{2}{*}{ Demographic characteristics } & \multirow{2}{*}{ Number of samples } & \multicolumn{2}{|l|}{ Prevalence of parasitism } & \multicolumn{2}{|l|}{ Chi-squared test } \\
\hline & & Number of infected individuals & $\%$ & Chi-squared value $\left(\chi^{2}\right)$ & $p$ value \\
\hline Occupation & & & & 5.1 & 0.278 \\
\hline Unemployed & $41(7.6 \%)$ & 11 & 26.8 & & \\
\hline Pupil & $82(15.2 \%)$ & 27 & 32.9 & & \\
\hline Petty trading & $30(5.6 \%)$ & 5 & 16.7 & & \\
\hline Sand winning & $47(8.7 \%)$ & 17 & 36.1 & & \\
\hline Farming & $338(62.8 \%)$ & 118 & 34.9 & & \\
\hline Type of farming & & & & 36.9 & $<0.0001$ \\
\hline Crop & $209(61.8 \%)$ & 98 & 46.9 & & \\
\hline Poultry & $47(13.9 \%)$ & 7 & 14.6 & & \\
\hline Livestock & $82(24.3 \%)$ & 13 & 15.8 & & \\
\hline
\end{tabular}

${ }^{\mathrm{a}}$ Other tribes were Frafra $(n=1)$, Guan $(n=2)$, Hausa $(n=3)$, and Krobo $(n=3) ;{ }^{\mathrm{b}}$ Buddhist $(n=2)$, Afrikanian mission $(n=4)$, unification movement $(n=4)$, and atheist $(n=5)$; ${ }^{c}$ income quoted in Ghana cedi (\$), exchange rate of 1 USD to 5.5 Ghana cedis.

\subsection{Microscopic Detection of Enteroparasites}

2.6.1. Detection of Enteroparasites Using Eosin-Saline Wet Preparation. On the same day of sample arrival in the laboratory, wet preparation was made to determine viable parasites. The stool sample was well mixed in its container and a drop transferred onto a microscope slide. The sample was emulsified on the slide using equal volume of normal saline and eosin mixture. The emulsified stool sample was examined using $\times 10$ and $\times 40$ objective of the microscope. Parasites were identified using their characteristic shape and motility [16].

\subsubsection{Detection of Enteroparasites Using Formol Ether} Concentration (FEC) Method. Stool samples were emulsified with saline $(0.9 \% \mathrm{NaCl})$ into a homogenous mixture. One $\mathrm{mL}$ of the homogenate was poured into a centrifuge tube after which $4.0 \mathrm{~mL}$ of formol-saline reagent was added. The mixture was vortexed vigorously before another $3.0 \mathrm{~mL}$ of $10 \%$ formol-saline was added. The content was mixed and sieved through a nonabsorbent sieve (3- or 4-folds). Subsequently, $3 \mathrm{~mL}$ of diethyl ether (Honeywell, USA: bp: $34.6^{\circ} \mathrm{C}$, $\mathrm{mp}:-116.3^{\circ} \mathrm{C}, \mathrm{mm}: 74.12 \mathrm{~g} / \mathrm{mol}$ ) was added and vortexed vigorously. The content was centrifuged at 3,000 rpm for 2 minutes. Supernatant was discarded, and iodine-mixed deposits were examined at $\times 10$ and $\times 40$. Parasite ova were identified using characteristic shapes [16].

2.7. Deworming of the Infected Individuals. Infected individuals were referred to nearby hospitals for treatment according to World Health Organization guidelines [17, 18]. Whereas praziquantel $(20 \mathrm{mg} / \mathrm{kg})$ was used to treat for $S$. mansoni, the other parasites were treated with albendazole $(400 \mathrm{mg})$. This treatment protocol was reviewed and approved by the Ghana Health Service Ethical Review Committee (Reference: GHS-REC002/03/18).

2.8. Outcome of the Study. The study reported overall and individual prevalence of enteroparasites identified in the study sites. The morphological characterization of the parasites was reported. Also, the frequencies of parasitism in the various age ranges, gender category, educational status, and occupation were reported. Finally, the effects of the parasites on nutritional status determined by body mass index, haemoglobin, and albumin concentrations were also reported.

2.9. Data Analysis. Frequencies were presented using percentages while prevalence was calculated based on the number of individuals parasitized divided by the total number of individuals tested in each category. Parasitism was classified as single, dual, and triple parasitism when one, two, or three different parasites were found in an individual. A chi-squared test was used to examine the association between infectious status and the independent variables while the logistic regression model was used as a post hoc analysis tool. Statistical analysis was done by SPSS Version 24 (Chicago, IL, USA). $p$ value of less than 0.05 was considered statistically significant.

\section{Results}

3.1. Demographic Characteristics of the Study Participants. Study participants $(n=538)$ were selected from five hardto-reach communities in Ga West Municipality, namely, Opah $(n=149)$, Otuaplem $(n=136)$, Dedeman $(n=105)$, Onyansana (83), and Manchie $(n=65)$. Majority of the participants $(61.5 \%)$ were males while the modal age range was 16-20 years. A little over $50 \%$ of the participants has never had formal education or has had only primary education. It was also found that $62.8 \%$ of the participants were farmers while the rest were either unemployed, pupils in primary school, petty traders, or sand winners. Of the 338 (62.8\%) farmers, $61.8 \%$ were crop farmers and $13.9 \%$ were poultry farmers while $24.3 \%$ were livestock farmers (Table 1 ).

3.2. Prevalence of Enteroparasitism. The overall prevalence of enteroparasitism in the hard-to-reach communities in the municipality was $33.1 \%$ (178/538) (95\% CI: 0.29-0.37). The most prevalent community was Opah (45.6\%) while Dedeman was the least prevalent (18.1\%). The other three communities were almost equiprevalent (30.1-34.9\%) (Figure 1). Prevalence of parasitism among males and females was $55.5 \%$ and $19.0 \%$, respectively. Community 
TABLE 2: Logistic regression analysis of significant associations of enteroparasitism with study variables.

\begin{tabular}{|c|c|c|c|c|c|c|}
\hline Study variables & $\beta$ & S.E. & Wald & $\mathrm{df}$ & Sig. & $\operatorname{Exp}(\beta)$ \\
\hline \multicolumn{7}{|l|}{ Resident community } \\
\hline Opah & 0.124 & 0.463 & 0.071 & 1 & 0.789 & 1.132 \\
\hline Otuaplem & -0.025 & 0.515 & 0.002 & 1 & 0.961 & 0.975 \\
\hline Dedeman & 0.810 & 0.484 & 2.798 & 1 & 0.094 & 2.247 \\
\hline Onyansana & 1.001 & 0.427 & 5.506 & 1 & $0.019^{*}$ & 2.722 \\
\hline \multicolumn{7}{|l|}{ Manchie (reference) } \\
\hline \multicolumn{7}{|l|}{ Age range (years) } \\
\hline $6-10$ & -2.067 & 4.537 & 0.208 & 1 & 0.649 & 0.127 \\
\hline $11-15$ & -2.973 & 1.654 & 3.228 & 1 & 0.072 & 0.051 \\
\hline $16-20$ & 3.375 & 1.223 & 7.615 & 1 & $0.006^{*}$ & 29.232 \\
\hline $21-25$ & 0.972 & 1.235 & 0.619 & 1 & 0.431 & 2.643 \\
\hline $26-30$ & -0.690 & 1.262 & 0.299 & 1 & 0.584 & 0.501 \\
\hline $31-35$ & -1.390 & 1.718 & 0.655 & 1 & 0.418 & 0.249 \\
\hline $36-40$ & -0.920 & 1.468 & 0.393 & 1 & 0.531 & 0.398 \\
\hline \multicolumn{7}{|l|}{$>40$ (reference) } \\
\hline \multicolumn{7}{|l|}{ Marital status } \\
\hline Single & 5.933 & 1.606 & 13.644 & 1 & $<0.001^{*}$ & 377.362 \\
\hline Married & 0.380 & 1.061 & 0.128 & 1 & 0.721 & 1.462 \\
\hline Widowed & 0.980 & 1.227 & 0.638 & 1 & 0.424 & 2.665 \\
\hline \multicolumn{7}{|l|}{ Divorced (reference) } \\
\hline \multicolumn{7}{|l|}{ Tribe } \\
\hline Akan & -2.964 & 1.213 & 5.969 & 1 & $0.015^{*}$ & 0.052 \\
\hline $\mathrm{Ga}$ & -2.169 & 1.281 & 2.865 & 1 & 0.090 & 0.114 \\
\hline Ewe & -2.175 & 1.113 & 3.820 & 1 & 0.051 & 0.114 \\
\hline Dagomba & -1.306 & 1.256 & 1.081 & 1 & 0.298 & 0.271 \\
\hline Fulani & -1.914 & 1.139 & 2.822 & 1 & 0.093 & 0.147 \\
\hline \multicolumn{7}{|l|}{ Others (reference) } \\
\hline \multicolumn{7}{|l|}{ Religion } \\
\hline Christianity & -1.006 & 0.464 & 4.709 & 1 & $0.030^{*}$ & 0.366 \\
\hline Islamic & 1.258 & 0.694 & 3.285 & 1 & 0.070 & 3.519 \\
\hline Traditional & -1.680 & 0.985 & 2.911 & 1 & 0.088 & 0.186 \\
\hline \multicolumn{7}{|l|}{ Others (reference) } \\
\hline \multicolumn{7}{|l|}{ Average monthly income } \\
\hline $0-500(0-90)$ & -1.715 & 1.004 & 2.915 & 1 & 0.088 & 0.180 \\
\hline $501-1000(91-181)$ & 0.118 & 0.428 & 0.075 & 1 & 0.784 & 1.125 \\
\hline $1001-1500(182-272)$ & -1.719 & 0.681 & 6.363 & 1 & $0.012^{*}$ & 0.179 \\
\hline \multicolumn{7}{|c|}{$1501-2000$ (273-363) (reference) } \\
\hline \multicolumn{7}{|l|}{ Highest education } \\
\hline None & -1.136 & 0.564 & 4.056 & 1 & $0.044^{*}$ & 0.321 \\
\hline Primary & -0.311 & 0.692 & 0.202 & 1 & 0.653 & 0.733 \\
\hline Junior high & -0.459 & 0.809 & 0.321 & 1 & 0.571 & 0.632 \\
\hline Senior high & -0.732 & 0.534 & 1.878 & 1 & 0.171 & 0.481 \\
\hline \multicolumn{7}{|c|}{ Postsenior high (reference) } \\
\hline \multicolumn{7}{|l|}{ Type of farming } \\
\hline Crop & -2.474 & 1.226 & 4.069 & 1 & $0.044^{*}$ & 0.084 \\
\hline Poultry & -1.611 & 0.910 & 3.138 & 1 & 0.076 & 0.200 \\
\hline Livestock & 0.443 & 1.205 & 0.135 & 1 & 0.713 & 1.558 \\
\hline Not applicable (refere & & & & & & \\
\hline
\end{tabular}

*Significantly different variable. 
dwellers up to 20 years were disproportionately parasitized (76.4\%) with individuals aged 16-20 years heavily parasitized (62.7\%). Again, community dwellers with no or only primary education were most parasitized (64.0\%) while those educated up to the postsecondary level were least parasitized (13.6\%). The prevalence of enteroparasitism was higher among sand winners, farmers, and primary school pupils $(36.1 \%, 34.9 \%$, and $32.9 \%$, respectively). Unemployed and petty traders were least parasitized even though the prevalence was higher in the unemployed $(26.8 \%)$ than petty traders $(16.7 \%)$. Among the farmers, the prevalence of parasitism was higher in crop farmers $(46.9 \%)$ than poultry (14.6\%) and livestock (15.8\%) farmers (Table 1).

3.3. Association of Infection Status with Study Variables. A chi-squared tool was used to test the association of infection status with independent variables. Whereas residential community $\left(\chi^{2}=21.9, p<0.0001\right)$, age of participants $\left(\chi^{2}=89.9\right.$, $p<0.0001)$, marital status $\left(\chi^{2}=67.9, p<0.0001\right)$, tribe $\left(\chi^{2}=61.8, p<0.0001\right)$, religious affiliation $\left(\chi^{2}=91.1, p<\right.$ $0.0001)$, average monthly income $\left(\chi^{2}=38.4, p<0.0001\right)$, educational level of participants $\left(\chi^{2}=37.1, p<0.0001\right)$, and farming type $\left(\chi^{2}=36.9, p<0.0001\right)$ were associated with infection status, gender $\left(\chi^{2}=1.1, p=0.301\right)$ and occupation of the participants $\left(\chi^{2}=5.1, p=0.278\right)$ were not associated (Table 1). Subsequently, gender and participants' occupation types were excluded from logistic regression analysis. Within the set of independent variables, logistic regression analysis indicated significantly higher infections in Onyansana $(p=0.019), 16-20$ years of age range $(p=0.006)$, unmarried participants $(p<0.001)$, those without formal education $(p=0.044)$, and crop farmers $(p=0.044)$. However, among the Akan tribe $(p=0.015)$, Christians $(p=0.03)$, and participants with higher incomes $(p=0.012)$, infections were found to be lower (Table 2).

3.4. Characterization and Prevalence of Enteroparasites. A cumulative total of 236 infections comprising seven parasite species were identified in 178 community dwellers. Both protozoa and helminths were identified. Three different protozoa were identified, namely, Giardia lamblia $(n=27,5.0 \%)$, Entamoeba histolytica $(n=39,7.2 \%)$, and Balantidium coli $(n=9,1.6 \%)$. Also, four different helminths were identified. They were Ascaris lumbricoides ( $n=37,6.9 \%)$, Schistosoma mansoni ( $n=72,13.4 \%)$, hookworm $(n=26,4.8 \%)$, and Strongyloides stercoralis $(n=26,4.8 \%)$. Among the 178 parasitized individuals, $121(68.0 \%)$ were singly infected with either G. lamblia, E. histolytica, B. coli, A. lumbricoides, S. mansoni, hookworm, or S. stercoralis. While $56(31.5 \%)$ of the community dwellers had dual parasitism, the common double parasitism was A. lumbricoides and S. mansoni (3.3\%) followed by A. lumbricoides and hookworm (2.4\%). However, B. coli and E. histolytica dual parasitism was rare $(0.7 \%)$. Only one $(0.18 \%)$ triple parasitism comprising $G$. lamblia, E. histolytica, and S. stercoralis was identified (Table 3).

3.5. Comparing Nutritional Status of Parasitized and Nonparasitized Community Dwellers. Over 60\% of parasit-
TABLE 3: Prevalence of single and coparasitism in study participants.

\begin{tabular}{lcc}
\hline Parasite & $\begin{array}{c}\text { Number of } \\
\text { participants }\end{array}$ & $\%$ \\
\hline Monoparasitism & 121 & 22.5 \\
Giardia lamblia & 12 & 2.2 \\
Entamoeba histolytica & 25 & 4.6 \\
Balantidium coli & 5 & 0.9 \\
Ascaris lumbricoides & 6 & 1.1 \\
Schistosoma mansoni & 47 & 8.7 \\
Hookworm & 6 & 1.1 \\
Strongyloides stercoralis & 20 & 3.7 \\
Dual parasitism & 56 & 10.4 \\
G. lamblia+E. histolytica & 9 & 1.7 \\
B. coli+E. histolytica & 4 & 0.7 \\
A. lumbricoides+hookworm & 13 & 2.4 \\
S. stercoralis+G. lamblia & 5 & 0.9 \\
A. lumbricoides+S. mansoni & 18 & 3.3 \\
S. mansoni+hookworm & 7 & 1.3 \\
Triple parasitism & 1 & 0.18 \\
G. lamblia+E. histolytica+S. stercoralis & & \\
\hline
\end{tabular}

ized participants were underweight while a little over $10 \%$ of the nonparasitized participants were underweight. Again, $68.0 \%$ of the parasitized participants had various forms of anaemia while $33.8 \%$ of the nonparasitized participants had various forms of anaemia. Finally, $64.5 \%$ of the parasitized participants were either malnourished or severely malnourished while $23.6 \%$ of the nonparasitized were malnourished, but none was severely malnourished (Table 4 ).

3.6. Frequency of Association of Enteroparasites with Nutritional Statuses. Three parasites (S. mansoni $(n=69$; $63.3 \%)$, hookworm $(n=27 ; 24.8 \%)$, and E. histolytica $(n=13 ; 11.9 \%))$ were identified in 109 participants that were underweight. With the exception of $B$. coli, the other parasites (A. lumbricoides, E. histolytica, G. lamblia, hookworm, S. mansoni, and S. stercoralis) were identified in participants with various forms of anaemia. Hookworm $(n=19 ; 61.3 \%)$, G. lamblia $(n=7 ; 22.6 \%)$, and S. mansoni $(n=5 ; 16.1 \%)$ were identified in severely anaemic study participants. Together with hookworm and S. mansoni, E. histolytica and A. lumbricoides were identified in moderately anaemic participants. Again, in mildly anaemic participants, hookworm $(n=11$, $35.5 \%), G$. lamblia $(n=9,29.0 \%)$, S. stercoralis $(n=7$, $22.6 \%)$, and E. histolytica $(n=4,12.9 \%)$ were identified. Finally, while G. lamblia (30.6\%), A. lumbricoides (29.2\%), hookworm (26.4\%), and E. histolytica (13.9\%) were identified in malnourished participants, S. stercoralis (39.5\%), hookworm (25.6\%), G. lamblia (23.3\%), and B. coli (11.6\%) were seen in severely malnourished participants (Table 5).

3.7. Impact of Parasitism on Nutritional Statuses. The mean BMI of monoparasitized individuals was significantly higher than individuals with dual parasitism (20.3 vs. $17.8 ; p=$ $0.035)$. Similarly, the mean haemoglobin concentration of 
TABLE 4: Anthropometric parameters and nutritional statuses of infected and noninfected study participants.

\begin{tabular}{|c|c|c|}
\hline Anthropometric features & $\begin{array}{l}\text { Number of infected } \\
\text { individuals }\end{array}$ & $\begin{array}{c}\text { Number of noninfected } \\
\text { individuals }\end{array}$ \\
\hline \multicolumn{3}{|l|}{ Body mass index $\left(\mathrm{kg} / \mathrm{m}^{2}\right)$} \\
\hline Underweight $(<18.5)$ & $109(61.2 \%)$ & $37(10.3 \%)$ \\
\hline Normal (18.5-24.9) & $55(30.9 \%)$ & $193(53.6 \%)$ \\
\hline Overweight (25.0-29.9) & $11(6.2 \%)$ & $66(18.3 \%)$ \\
\hline Obese $(>30.0)$ & $3(1.7 \%)$ & $64(17.8 \%)$ \\
\hline \multicolumn{3}{|l|}{ Anaemia assessment } \\
\hline Severe anaemia $(\mathrm{Hb}<8.0 \mathrm{~g} / \mathrm{dL})$ & $31(17.4 \%)$ & $21(5.8 \%)$ \\
\hline Moderate anaemia ( $\mathrm{Hb} 8.0-10.9 \mathrm{~g} / \mathrm{dL})$ & $59(33.1 \%)$ & $80(22.2 \%)$ \\
\hline Mild anaemia $(11.0-11.9 \mathrm{~g} / \mathrm{dL})$ & $31(17.4 \%)$ & $95(26.4 \%)$ \\
\hline Nonanaemic $(\mathrm{Hb}>12.0 \mathrm{~g} / \mathrm{dL})$ & $57(32.0 \%)$ & $164(45.6 \%)$ \\
\hline \multicolumn{3}{|l|}{ Serum albumin levels } \\
\hline Values above mean minus 1SD (normal) & $63(35.4 \%)$ & $275(76.4 \%)$ \\
\hline Values below mean minus 1 SD and above mean 2SD (malnourished) & $72(40.4 \%)$ & $85(23.6 \%)$ \\
\hline Values below mean minus 2SD (severely malnourished) & $43(24.1 \%)$ & $0(0.0 \%)$ \\
\hline
\end{tabular}

In the infected group, mean albumin concentration was $41.4 \mathrm{~g} / \mathrm{L}$ while the standard deviation (SD) was $6.7 \mathrm{~g} / \mathrm{L}$. Mean minus $1 \mathrm{SD}$ was $34.7 \mathrm{~g} / \mathrm{L}$ while mean minus $2 \mathrm{SD}$ was $28.0 \mathrm{~g} / \mathrm{L}$. In the noninfected group, mean albumin was $44.3 \mathrm{~g} / \mathrm{L}$ and $\mathrm{SD}$ was $5.3 \mathrm{~g} / \mathrm{L}$. Mean minus $1 \mathrm{SD}$ was $39.0 \mathrm{~g} / \mathrm{L}$ while mean minus $2 \mathrm{SD}$ was $33.7 \mathrm{~g} / \mathrm{L}$.

TABLE 5: Distribution of enteroparasites in underweight, anaemic, and malnourished participants.

\begin{tabular}{|c|c|c|}
\hline Nutritional status & $\begin{array}{l}\text { Associated } \\
\text { parasites }\end{array}$ & $\begin{array}{c}\text { Frequency of } \\
\text { association } \\
\text { with nutritional } \\
\text { status }\end{array}$ \\
\hline \multirow{3}{*}{ Underweight $(n=109)$} & S. mansoni & $69(63.3 \%)$ \\
\hline & Hookworm & $27(24.8 \%)$ \\
\hline & E. histolytica & $13(11.9 \%)$ \\
\hline \multirow{3}{*}{ Severe anaemia $(n=31)$} & Hookworm & $19(61.3 \%)$ \\
\hline & G. lamblia & $7(22.6 \%)$ \\
\hline & S. mansoni & $5(16.1 \%)$ \\
\hline \multirow{4}{*}{ Moderate anaemia $(n=59)$} & Hookworm & $22(37.3 \%)$ \\
\hline & E. histolytica & $19(32.2 \%)$ \\
\hline & S. mansoni & $9(15.3 \%)$ \\
\hline & A. lumbricoides & $9(15.3 \%)$ \\
\hline \multirow{4}{*}{ Mild anaemia $(n=31)$} & Hookworm & $11(35.5 \%)$ \\
\hline & G. lamblia & $9(29.0 \%)$ \\
\hline & S. stercoralis & $7(22.6 \%)$ \\
\hline & E. histolytica & $4(12.9 \%)$ \\
\hline \multirow{4}{*}{ Malnourished $(n=72)$} & G. lamblia & $22(30.6 \%)$ \\
\hline & A. lumbricoides & $21(29.2 \%)$ \\
\hline & Hookworm & $19(26.4 \%)$ \\
\hline & E. histolytica & $10(13.9 \%)$ \\
\hline \multirow{4}{*}{ Severely malnourished $(n=43)$} & S. stercoralis & $17(39.5 \%)$ \\
\hline & Hookworm & $11(25.6 \%)$ \\
\hline & G. lamblia & $10(23.3 \%)$ \\
\hline & B. coli & $5(11.6 \%)$ \\
\hline
\end{tabular}

monoparasitized individuals was significantly higher than dual parasitized individuals (9.8 vs. $7.7 ; p=0.018$ ). Also, mean albumin concentration in monoparasitized individuals was higher than the mean concentration obtained for dual parasitism (31.9 vs. $27.6 ; p=0.042$ ). Surprisingly, the BMI of the only triple parasitized individual was higher than the mean values found in mono- and dual parasitism. Again, the haemoglobin concentration in triple parasitism was higher than the mean haemoglobin concentration in mono- and dual parasitism, but the albumin concentration for triple parasitism was higher than dual parasitism but lower than monoparasitism (Table 6).

\section{Discussion}

This study reports, for the first time, the prevalence of parasitic infections in the Ga West Municipality in the Greater Accra Region of Ghana. In this study, the overall parasitism in hard-to-reach communities in the municipality was $33.1 \%$. In all, three protozoa, Giardia lamblia, Entamoeba histolytica, and Balantidium coli, and four helminths, three geohelminths (Ascaris lumbricoides, Strongyloides stercoralis, and hookworm), and one water-transmitted parasite, Schistosoma mansoni, were identified. Identification of these enteroparasites in hard-to-reach residents was consistent with previous studies that also identified protozoa and helminths in rural settings [19-24].

It is noteworthy that this study is the first to identify $B$. coli infections in humans in Ghana. However, a previous study in 2018 detected B. coli in commonly consumed vegetables collected from the Eastern Region of Ghana [25], a region that shares direct boundary with the Ga West Municipality. The prevalence of B. coli was $1.7 \%$ (9/538); five infections were single parasitism while four were seen 
TABLE 6: Differences in haemoglobin, albumin levels, and BMI in categories of parasitism.

\begin{tabular}{|c|c|c|c|c|}
\hline Nutritional indicator & Monoparasitism $(n=121)$ & Dual parasitism $(n=56)$ & Triple parasitism $(n=1)$ & $p$ value* \\
\hline Body mass index & $20.3 \mathrm{~kg} / \mathrm{m}^{2 *}$ & $17.8 \mathrm{~kg} / \mathrm{m}^{2 *}$ & $24.5 \mathrm{~kg} / \mathrm{m}^{2}$ & 0.035 \\
\hline Haemoglobin concentration & $9.8 \mathrm{~g} / \mathrm{dL}^{*}$ & $7.7 \mathrm{~g} / \mathrm{dL}^{*}$ & $10.7 \mathrm{~g} / \mathrm{dL}$ & 0.018 \\
\hline Albumin concentration & $31.9 \mathrm{~g} / \mathrm{L}^{*}$ & $27.6 \mathrm{~g} / \mathrm{L}^{*}$ & $28.5 \mathrm{~g} / \mathrm{L}$ & 0.042 \\
\hline
\end{tabular}

${ }^{*} p$ values were determined by a $t$-test. Analysis determined differences in nutritional indicators in mono- and dual parasitism only excluding triple parasitism due to its single occurrence.

together with E. histolytica. These parasites were identified in two livestock-rearing communities, namely, Opah and Onyansana. Pigs are known to be a reservoir of B. coli, and humans become infected through direct or indirect contact with pig droppings [26]. As observed in this study, B. coli is largely prevalent in rural areas in developing countries. Due to the possibility of pig and human fecal matter-containing rivers and streams [26], people who do not reside in pigrearing communities may also be at risk of balantidiosis. $B$. coli is highly prevalent in Latin America, the Philippines, Papua New Guinea, and areas of the Middle East [27, 28]. The prevalence of $B$. coli in these regions is close to $29 \%$ in pig and other farmers [29, 30]. However, B. coli infection has the potential for worldwide distribution [30]. It is not too clear how B. coli was transported into Ghana, but it is possible that the parasite is prevalent in pig farmers in Ghana, as published previously [25], but lack of surveillance activities for the parasites makes it appear that it does not exist in Ghana. B. coli could be an emerging parasitic infection in rural Ghana where pigs are being reared.

This study found that males, residents less than 20 years, individuals with no or only primary education as well as pupils, sand winners, and crop farmers were disproportionally infected. Young adult males have been found to be at higher risk of parasitic infections due to their frequent outdoor activities that keep them in constant contact with infected soil [31-33]. Again, in rural Ghana, proper toilet facilities have been found to be lacking with common open defecation [34]. This unhygienic practice contaminates the soil with faeces containing parasite ova and cyst. This also makes land tillers such as crop farmers and sand winners highly vulnerable to parasitic infections. Again, this study found half $(50 \%)$ of the schoolchildren to be infected with various parasites. This finding is consistent with previous studies that found schoolchildren to be at higher risk of parasitism due to their constant contact with the soils [35-39] coupled with poor hygienic environment in rural areas as well as unhygienic practices such as poor hand-washing practices, walking barefooted, and touching their mouths with unclean hands. Education has also been found to be associated with parasitic infections with low education associated with high rates of infections. In this study, $64.0 \%$ of the study participants with no or only primary education were most parasitized. This is because well-educated people are able to understand and adhere to parasite control practices [40] that have the ultimate outcome of reducing parasitic infections. Also, lack of potable water in the study communities made the community members depend on streams and rivers. This led to high prevalence of $S$. mansoni (13.4\%) with males between 8 and 20 years predominantly infected.

This study found $31.5 \%$ of coparasitism in the community dwellers. The most common dual parasitism was $A$. lumbricoides/S. mansoni (10.0\%), A. lumbricoides/hookworm (7.3\%), and G. lamblia/E. histolytica (5.0\%). Comparing to monoparasitism, dual parasitism was significantly associated with various degrees of anaemia, underweight, and moderate to severe malnourishment. This study, though confirming separate earlier reports $[36,37,41]$, associated dual parasitism to underweight, anaemia, and malnourishment in the same parasitized individuals. Persistent parasitism is suggested to cause stunted growth due to the competition of the parasites with the host for essential nutrients [38, 39, 42]. Again, parasites such as S. mansoni, hookworm, and E. histolytica are known to impact anaemia to their host. E. histolytica trophozoites have been shown to depend on iron for their metabolism, reproduction, and survival inside the host [43] while S. mansoni has been found to cause anaemia through inflammatory response [35]. Hookworm is also known to cause iron deficiency anaemia by competing with the host for iron [44]. The clinical effects of these parasites on their hosts call for intense screening of residents of hardto-reach communities for enteric parasites and also implementation of regular mass drug administration exercises to reduce enteroparasitism in these communities.

\section{Conclusion}

This study reports, for the first time, the prevalence and microscopic characterization of enteroparasites in hard-toreach communities in the Ga West Municipality, Ghana. G. lamblia, E. histolytica, B. coli, A. lumbricoides, S. stercoralis, hookworm, and $S$. mansoni were identified at different frequencies. In this study, community dwellers above 5 years were examined due to difficulty in getting stool samples from children under 5 years. Assessing the prevalence of enteroparasites in children under 5 will complement this study. Again, this study identified B. coli for the first time in humans in Ghana. The number of B. coli infections identified was not enough to describe their clinical significance on their host. But it was found that the stool samples that contained them were loose to watery. Dual parasitism was found to be associated with underweight, anaemia, and malnutrition. Education on personal hygiene with the aim of prevention of parasitic infections must be intensified in the municipality. Mass deworming exercise in the entire municipality is also recommended. After implementation of these control 
measures, future studies to reassess the persistence of enteroparasites in these communities are recommended.

\section{Data Availability}

All data obtained in this study have been presented in the manuscript.

\section{Ethical Approval}

Ethical clearance for this study was obtained from the Ghana Health Service Ethical Review Committee (GHSREC002/03/18).

\section{Conflicts of Interest}

The authors declare that there is no conflict of interests to declare.

\section{Acknowledgments}

The authors acknowledge the roles played by Isaac Acquah, Dorcas Biney, and Alex Nyarko during the sample collection stage of this study. Also, the chiefs and the community leaders, whose communities this study was done, are well appreciated. Finally, we acknowledge the Municipal Health Director for assisting us to carry out this study.

\section{References}

[1] T. Rufai, E. Aninagyei, S. O. Sackey, E. Kenu, and E. A. Afari, "Evaluation of Buruli ulcer disease surveillance system in the Ga West Municipality, Ghana, 2011-2015," Journal of Tropical Medicine, vol. 2019, Article ID 4721236, 5 pages, 2019.

[2] Ghana Statistical Service, Population and Housing Census, 2010.

[3] A. Y. Ami, "Accessing water for domestic use: the challenges faced in the Ga West Municipality, Ghana," International Journal of Social Science and Humanities Research, vol. 2, no. 2, pp. 78-91, 2014.

[4] R. Y. Kofie, E. M. Attua, and J. S. Nabila, "Poverty and socioeconomic consequences of Buruli ulcer (Mycobacterium ulcerans) in the Ga West District of Ghana," Norsk Geografisk Tidsskrift - Norwegian Journal of Geography, vol. 62, no. 3, pp. 210-221, 2008.

[5] C. Kwakye-Maclean, N. Agana, J. Gyapong et al., "A single dose oral azithromycin versus intramuscular benzathine penicillin for the treatment of yaws-a randomized non inferiority trial in Ghana," PLoS Neglected Tropical Diseases, vol. 11, no. 1, article e0005154, 2017.

[6] B. Y. Adomako, P. Nana Yaw, and M. Kezia, "Evaluation of the Ga West Municipality tuberculosis surveillance system in the Greater Accra Region of Ghana," Ghana Weekly Epidemiological Report, vol. 2, no. 37, pp. 18-22, 2017.

[7] D. Yeboah-Manu, P. Asare, A. Asante-Poku et al., "Spatiotemporal distribution of Mycobacterium tuberculosis complex strains in Ghana," PLoS One, vol. 11, no. 8, article e0161892, 2016.

[8] R. Nyarko, K. Torpey, and A. Ankomah, "Schistosoma haematobium, Plasmodium falciparum infection and anaemia in children in Accra, Ghana," Tropical Diseases, Travel Medicine and Vaccines, vol. 4, no. 1, p. 3, 2018.

[9] M. E. Aryeetey, Y. Wagatsuma, G. Yeboah et al., "Urinary schistosomiasis in southern Ghana: 1 . Prevalence and morbidity assessment in three (defined) rural areas drained by the Densu river," Parasitology International, vol. 49, no. 2, pp. 155-163, 2000.

[10] J. Charan and T. Biswas, "How to calculate sample size for different study designs in medical research?," Indian Journal of Psychological Medicine, vol. 35, no. 2, pp. 121-126, 2013.

[11] N. G. Norgan, "Population differences in body composition in relation to the BMI," European Journal of Clinical Nutrition, vol. 48, Supplement 3, pp. S10-S27, 1994.

[12] G. Prenner, A. Wasler, A. Fahrleinter-Pammer et al., "The role of serum albumin in the prediction of malnutrition in patients at least five yr after heart transplantation," Clinical Transplantation, vol. 28, no. 6, pp. 737-742, 2014.

[13] World Health Organization, "Body mass index - BMI," June 2020, https://www.euro.who.int/en/health-topics/diseaseprevention/nutrition/a-healthy-lifestyle/body-mass-indexbmi.

[14] WHO, "Haemoglobin concentrations for the diagnosis of anaemia and assessment of severity," in Vitamin and Mineral Nutrition Information System, World Health Organization, Geneva, 2011, June 2020, http://www.who.int/vmnis/ indicators/haemoglobin.

[15] O. O. Omitola, H. O. Mogaji, A. S. Oluwole, A. A. Adeniran, O. M. Alabi, and U. F. Ekpo, "Geohelminth infections and nutritional status of preschool aged children in a periurban settlement of Ogun State," Scientifica, vol. 2016, Article ID 7897351, 9 pages, 2016.

[16] L. S. Garcia, M. Arrowood, E. Kokoskin et al., "Practical Guidance for Clinical Microbiology Laboratories: Laboratory diagnosis of parasites from the gastrointestinal tract," Clinical Microbiology Reviews, vol. 31, no. 1, 2018.

[17] Preventive chemotherapy to control soil-transmitted helminth infections in at-risk population groups, World Health Organization, Geneva, 2017, http://www.who.int/elena/titles/full_ recommendations/deworming/en/.

[18] M. Amarillo, R. Martinez, A. Mallari, C. Tai, and V. Belizario, "Efficacy and safety of $40 \mathrm{mg} / \mathrm{kg}$ and $60 \mathrm{mg} / \mathrm{kg}$ doses of praziquantel in the treatment of schistosomiasis," Journal of Pediatric Infectious Diseases, vol. 3, pp. 27-34, 2008.

[19] L. F. Nimri and M. Meqdam, "Enteropathogens associated with cases of gastroenteritis in a rural population in Jordan," Clinical Microbiology and Infection, vol. 10, no. 7, pp. 634639, 2004.

[20] E. R. Machado, T. S. De Souza, J. M. Da Costa, and J. M. CostaCruz, "Enteroparasites and commensals among individuals living in rural and urban areas in Abadia dos Dourados, Minas Gerais state, Brazil,” Parasitología latinoamericana, vol. 63, no. 1-2-3-4, pp. 34-39, 2008.

[21] L. Quihui, M. E. Valencia, D. W. T. Crompton et al., "Role of the employment status and education of mothers in the prevalence of intestinal parasitic infections in Mexican rural schoolchildren," BMC Public Health, vol. 6, no. 1, p. 225, 2006.

[22] M. L. Galvan-Ramirez, N. Rivera, M. E. Loeza et al., "Nitazoxanide in the treatment ofAscaris lumbricoidesin a rural zone of Colima, Mexico," Journal of Helminthology, vol. 81, no. 3, pp. 255-259, 2007. 
[23] L. Nyantekyi, M. Legesse, G. Medhin et al., "Community awareness of intestinal parasites and the prevalence of infection among community members of rural Abaye Deneba area, Ethiopia," Asian Pacific Journal of Tropical Biomedicine, vol. 4, Supplement 1, pp. S152-S157, 2014.

[24] K. N. Opara, N. I. Udoidung, D. C. Opara, O. E. Okon, E. U. Edosomwan, and A. J. Udoh, "The impact of intestinal parasitic infections on the nutritional status of rural and urban school aged children in Nigeria," International Journal of MCH and AIDS, vol. 1, no. 1, pp. 73-82, 2012.

[25] C. Kudah, S. Sovoe, and F. Baiden, "Parasitic contamination of commonly consumed vegetables in two markets in Ghana," Ghana Medical Journal, vol. 52, no. 2, pp. 88-93, 2018.

[26] F. L. Schuster and L. Ramirez-Avila, "Current world status of Balantidium coli," Clinical Microbiology Reviews, vol. 21, no. 4, pp. 626-638, 2008.

[27] S. Yazar, F. Altuntas, I. Sahin, and M. Atambay, "Dysentery caused by Balantidium coli in a patient with non-Hodgkin's lymphoma from Turkey," World Journal of Gastroenterology, vol. 10, no. 3, pp. 458-459, 2004.

[28] S. Solaymani-Mohammadi, M. Rezaian, H. Hooshyar, G. R. Molavi, Z. Babaei, and M. A. Anwar, "Intestinal protozoa in wild boars (Sus scrofa) in western Iran," Journal of Wildlife Diseases, vol. 40, no. 4, pp. 801-803, 2004.

[29] L. L. Owen, "Parasitic zoonoses in Papua New Guinea," Journal of Helminthology, vol. 79, no. 1, pp. 1-14, 2005.

[30] J. G. Esteban, R. Angles, S. Mas-Coma, C. Aguirre, and L. R. Ash, "Balantidiasis in Aymara children from the northern Bolivian Altiplano," The American Journal of Tropical Medicine and Hygiene, vol. 59, no. 6, pp. 922-927, 1998.

[31] E. O. Dada, "Prevalence of human intestinal helminthes among primary school children in Ipogun, Ifedore local government area Nigeria," Journal of Global Biosciences, vol. 5, no. 1, pp. 3401-3407, 2016.

[32] M. Abide, E. Nibret, and A. Munshea, "Prevalence of intestinal helminthic infections and malnutrition among school children of the Zegie Peninsula, northwestern Ethiopia," Journal of Infection and Public Health, vol. 10, pp. 84-92, 2017.

[33] G. Gebretsadik, "Prevalence of intestinal parasites and associated risk factors among schoolchildren of Homesha District (woreda) in Benishangul-Gumuz regional State, western Ethiopia," Journal of Family Medicine and Health Care, vol. 2, no. 4, pp. 57-64, 2016.

[34] I. K. Osumanu, E. A. Kosoe, and F. Ategeeng, "Determinants of open defecation in the Wa Municipality of Ghana: empirical findings Highlighting sociocultural and economic dynamics among households," Journal of Environmental and Public Health, vol. 2019, Article ID 3075840, 10 pages, 2019.

[35] S. E. Butler, E. M. Muok, S. P. Montgomery et al., "Mechanism of anemia in Schistosoma mansoni-infected school children in Western Kenya," The American Journal of Tropical Medicine and Hygiene, vol. 87, no. 5, pp. 862-867, 2012.

[36] N. Yentür Doni, F. Yıdız Zeyrek, Z. Simşek, and D. Zeyrek, "The effects of intestinal parasites on anemia of children," Türkiye Parazitolojii Dergisi, vol. 38, no. 2, pp. 85-90, 2014.

[37] O. C. Ihejirika, O. C. Nwaorgu, C. I. Ebirim, and C. M. Nwokeji, "Effects of intestinal parasitic infections on nutritional status of primary children in Imo State Nigeria," Pan African Medical Journal, vol. 33, no. 34, 2019.
[38] L. Francis, B. E. Kirunda, and C. G. Orach, "Intestinal helminth infections and nutritional status of children attending primary schools in Wakiso District, Central Uganda," International Journal of Environmental Research and Public Health, vol. 9, pp. 2910-2921, 2012.

[39] M. Wolde, Y. Berhan, and A. Chala, "Determinants of underweight, stunting and wasting among schoolchildren," BMC Public Health, vol. 15, no. 1, p. 8, 2015.

[40] J. Dhanabal, P. P. Selvadoss, and K. Muthuswamy, "Comparative study of the prevalence of intestinal parasites in low socioeconomic areas from South Chennai, India," Journal of Parasitology Research, vol. 2014, Article ID 630968, 7 pages, 2014.

[41] T. Hailegebriel, "Undernutrition, intestinal parasitic infection and associated risk factors among selected primary school children in Bahir Dar, Ethiopia," BMC Infectious Diseases, vol. 18, no. 1, p. 394, 2018.

[42] Y. Rajoo, S. Ambu, Y. A. L. Lim et al., "Neglected intestinal parasites, malnutrition and associated key factors: a population based cross-sectional study among indigenous communities in Sarawak, Malaysia," PLoS One, vol. 12, no. 1, article e0170174, 2017.

[43] I. De Domenico, D. McVey Ward, and J. Kaplan, "Regulation of iron acquisition and storage: consequences for iron-linked disorders," Nature Reviews. Molecular Cell Biology, vol. 9, no. 1, pp. 72-81, 2008.

[44] J. L. Smith and S. Brooker, "Impact of hookworm infection and deworming on anaemia in non-pregnant populations: a systematic review," Tropical Medicine \& International Health, vol. 15, no. 7, pp. 776-795, 2010. 